\title{
Commentary Improvements in the outcome of children with meningococcal disease
}

\author{
Fauzia Paize ${ }^{1}$ and Stephen D Playfor ${ }^{2}$ \\ 'Institute of Child Health, University of Liverpool, Eaton Road, Liverpool, L12 2AP, United Kingdom \\ 2Paediatric Intensive Care Unit, Royal Manchester Children's Hospital, Hospital Road, Pendlebury, Manchester, M27 4HA, United Kingdom
}

Corresponding author: Stephen D Playfor, Stephen.playfor@cmmc.nhs.uk

Published: 29 October 2007

This article is online at http://ccforum.com/content/11/5/172

(C) 2007 BioMed Central Ltd

See related research by Maat et al., http://ccforum.com/content/11/5/R112

\begin{abstract}
Recent years have seen a marked reduction in the mortality of children with meningococcal disease in paediatric intensive care units (PICU); the reasons for this improvement are multifactorial. The mortality rates for critically ill children overall have improved and reasons for this are probably increased centralisation of PICU services and that fewer critically ill children are now looked after on adult units. Specific treatment pathways for sepsis have improved with the publication of clinical guidelines for children and initiatives such as the Surviving Sepsis Campaign. There is a continuing need to focus on the care delivered to children before reaching PICU and to minimise the morbidity suffered by survivors of this disease.
\end{abstract}

Meningococcal disease (MCD) continues to be the most common infective cause of death in children. In this issue of the journal, Maat et al. describe a paediatric intensive care unit (PICU) based study describing their experience of managing children with MCD (specifically, sepsis and purpura) over an 18 year period [1]. They are in the unusual and valuable position of having collected their data prospectively. The authors found that survival of children presenting to their unit with MCD correlated with year of admission indicating a significant ongoing reduction in case fatality. Indeed, the authors have not seen a single death in PICU from sepsis and purpura on their unit since 2002. These findings reflect the significant reduction in mortality seen in MCD in the UK and elsewhere over recent years [2,3]. Maat and colleagues attribute the improvement in outcome in part to changes in PICU management and resuscitation practices, but the reasons are undoubtedly multifactorial.

Over the last decade there has been a significant improvement in mortality rates in PICU generally [4,5]. These trends have been much more easily examined in the UK since the establishment of the Paediatric Intensive Care Audit Network (PICANet) in 2002; an audit database recording details of the treatment of all critically ill children in NHS PICUs in England, Wales and Scotland (Edinburgh).

There has also been a move towards increased centralisation of PICU services with fewer critically ill children being treated in adult units over recent years. This trend is founded on studies such as that of Pearson who demonstrated an excess mortality and a greater length of stay in a region of the UK with decentralised PICU services compared to the centralised service of Victoria, Australia [6]. Similar findings have been demonstrated in the USA and the Netherlands [7].

There has been an improvement in the awareness, diagnosis and management of patients with sepsis in emergency departments and critical care units since the recent publication of clinical practice guidelines for children with severe sepsis by Carcillo [8] drawing together the evidence of benefit from aggressive early fluid resuscitation and inotrope therapy. We have also seen the launch of the Surviving Sepsis Campaign with the publication of clinical practice guidelines [9] and the evolution of sepsis 'care bundles' which have improved mortality. A specific MCD management algorithm was published in the UK in 1999; a document which has been extensively distributed and utilised throughout emergency departments and paediatric units and which has been recently updated [10].

Maat et al. set out to study the epidemiology of sepsis and purpura in children 'referred to the PICU' and acknowledge that deaths prior to PICU admission are not addressed. Changes in PICU practice may lead to an increase in these 'hidden' MCD deaths. In a highly centralised PICU system

$\mathrm{MCD}=$ meningococcal disease; PICANet = Paediatric Intensive Care Audit Network; PICU = paediatric intensive care unit. 
where highly equipped PICU teams travel over great distances, often by air, a significant number of critically ill children may receive early and prolonged care from a PICU team in a referring hospital. If children such as these succumb to their illness before returning to the central PICU, then they may not contribute to published PICU mortality figures. True population based studies of MCD mortality are of crucial importance; a study of this kind carried out in the USA found that MCD mortality rates increased from 1990 to 1997 and decreased from 1998 to 2002 [11].

Policies to reduce mortality in the UK have been designed to raise awareness at every step of the patient journey. Public awareness had been raised with the help of charities such as the Meningitis Research Foundation highlighting the need for parents to seek medical help early for children with a high temperature and a non-blanching rash (identified using the 'tumbler test') and stressing the importance of receiving the meningococcal serogroup $\mathrm{C}$ conjugate vaccine. In November 1999, the UK became the first country to incorporate this vaccine into a national immunisation programme. Following this, disease attack rates dropped in the vaccinated, carriage rates dropped and the incidence declined among unvaccinated persons, suggesting the development of herd immunity.

A recent study has demonstrated that up to half of all children presenting to hospital with MCD had previously been discharged home following a primary care assessment [12]. Strategies to increase awareness in primary care have targeted the recognition of presenting clinical features and the administration of penicillin to children prior to transfer to hospital [13].

Ninis et al. determined three factors that were independently associated with an increased risk of death in children with MCD after admission to the district hospital. These were failure to be looked after by a paediatrician, failure of sufficient supervision of junior staff, and failure of staff to administer adequate inotropes [14]. The involvement of a skilled multidisciplinary paediatric team in the resuscitation, stabilisation and transfer of any critically ill child with sepsis is paramount and if carried out well will lead to an improvement in outcome [15].

Survivors of invasive disease may sustain permanent sequelae, such as deafness, seizures, limb amputation or tissue loss, chronic renal impairment and developmental delay. Maat et al. did not examine morbidity in their large cohort, which would have been clinically highly relevant; there is little published data on changes in the rate of morbidity due to MCD over recent years. As with clinical conditions such as leukaemia, an improvement in overall mortality inevitably leads to greater focus on the quality of life of survivors with survival being at minimum cost rather than at any cost.

\section{Competing interests}

The authors have no competing interests.

\section{References}

1. Maat M, Buysse CMP, Emonts M, Spanjaard L, Joosten KFM, de Groot RDE, Hazelzet JA: Improved survival of children with sepsis and purpura: effects of age, gender and era. Crit Care 2007, 11:R112.

2. Booy R, Habibi P, Nadel S, de Munter C, Britto J, Morrison A, Levin M; Meningococcal Research Group: Reduction in case fatality rate from meningococcal disease associated with improved healthcare delivery. Arch Dis Child 2001, 85:386390.

3. Thorburn K, Baines $\mathrm{P}$, Thomson A, Hart CA: Mortality in severe meningococcal disease. Arch Dis Child 2001, 85:382-385.

4. Carcillo JA: What's new in pediatric intensive care. Crit Care Med 2006, 34:S183-190.

5. Tilford JM, Roberson PK, Lensing S, Fiser DH: Differences in pediatric ICU mortality risk over time. Crit Care Med 1998, 26: 1737-1743.

6. Pearson G, Shann F, Barry P, Vyas J, Thomas D, Powell C, Field $D$ : Should paediatric intensive care be centralised? Trent versus Victoria. Lancet 1997, 349:1213-1217.

7. Gemke RJ, Bonsel GJ: Comparative assessment of pediatric intensive care: a national multicenter study. Pediatric Intensive Care Assessment of Outcome (PICASSO) Study Group. Crit Care Med 1995, 23:238-245.

8. Carcillo JA, Fields Al: American College of Critical Care Medicine Task Force Committee Members Clinical practice parameters for hemodynamic support of pediatric and neonatal patients in septic shock. Crit Care Med 2002, 30:1365-1378.

9. Dellinger RP, Carlet JM, Masur H, Gerlach H, Calandra T, Cohen J, Gea-Banacloche J, Keh D, Marshall JC, Parker MM, et al.: Surviving Sepsis Campaign guidelines for management of severe sepsis and septic shock. Crit Care Med 2004, 32:858873.

10. Pollard AJ, Nadel S, Ninis N, Faust SN, Levin M: Emergency management of meningococcal disease: eight years on. Arch Dis Child 2007, 92:283-286.

11. Sharip A, Sorvillo F, Redelings MD, Mascola L, Wise M, Nguyen DM: Population-based analysis of meningococcal disease mortality in the United States: 1990-2002. Pediatr Infect Dis $J$ 2006, 25:191-194.

12. Gupta RK, Chadha A: Clinical recognition of meningococcal disease. Lancet 2006, 367:1395.

13. Hahne SJ, Charlett A, Purcell B, Samuelsson S, Camaroni I, Ehrhard I, Heuberger S, Santamaria M, Stuart JM: Effectiveness of antibiotics given before admission in reducing mortality from meningococcal disease: systematic review. BMJ 2006, 332:1299-1303.

14. Ninis N, Phillips C, Bailey L, Pollock Jl, Nadel S, Britto J, Maconochie I, Winrow A, Coen PG, Booy R: The role of healthcare delivery in the outcome of meningococcal disease in children: case-control study of fatal and non-fatal cases. BMJ 2005, 330:1475.

15. Peters M, Petros A, Baines $P$, Loan P, Cullen P, Ralston C, Yates $R$, Marsh $M$, Weir $P$ : Genuine reduction in meningococcal deaths results from teamwork. Arch Dis Child 2002, 87:560561. 